\title{
Ultrastructure of the Excretory Tubes of the Mite Macrocheles muscaedomesticae (Mesostigmata, Macrochelidae) with Notes on Altered Mitochondria
}

\author{
LEWIS B. COONS AND RICHARD C. AXTELL \\ Department of Entomology, North Carolina State University, \\ Raleigh, North Carolina 27607
}

\begin{abstract}
The fine structure of the excretory tubes of the mesostigmatid mite Macrocheles muscaedomesticae were investigated. These paired tubes are partially ensheathed by fat body and invested throughout by a branching system of visceral muscles. The fine structure of the cells of the excretory tube is in general similar with only minor differences found throughout its length. The basal region of each epithelial cell of the excretory tube borders the hemocoel and is divided into many compartments by the extensive infolding of the plasma membrane. Mitochondria and vacuolar inclusions are often closely associated with these compartments. More than one morphological type of mitochondria was found distributed throughout the cells of the excretory tubes. The most commonly encountered type had well developed cristae and an electron dense matrix. Less commonly, mitochondria with somewhat poorly developed cristae and a translucent matrix often containing myelin-like figures of varying complexity were observed. It is suggested that they represent part of a normal process of mitochondrial degeneration. The apical region of the cell has a border composed of plate-like folds of the plasma membrane termed microlamellae. The lumen contains abundant granules of the excretory product.
\end{abstract}

Aside from the insects, the mites are the most widely diversified group of arthropods with respect to habitat. They have adapted to a wide variety of environmental conditions. This has resulted in several different approaches to the problem of nitrogenous waste removal. Three types of excretory organs are found within the Acarina: coxal glands, excretory tubes, and, in the Trombidiformes, a modified hindgut (Baker and Wharton, '52). Excretory tubes that open into the hindgut, such as found in the Macrochelidae, are the most common type of excretory organ.

This paper presents the results of an ultrastructural study on the excretory tubes of Macrocheles muscaedomesticae (Scopoli), a free living terrestrial mite that feeds on the eggs of the housefly, Musca domestica $\mathrm{L}$. This mite has a number of features advantageous to this type of study. It is a relatively large mite (about $1.1 \mathrm{~mm}$ in length), is easily reared in large num- bers in the laboratory, and is a representative of free living mesotigmatid mites and is less specialized than many of the parasitic forms.

\section{MATERIALS AND METHODS}

Mites used in this study were obtained from laboratory cultures mass reared in plastic dishes in a substrate of fresh cow manure mixed equally with CSMA medium which had been used to raise housefly larvae. Colonies were fed a mixture of housefly eggs, previously frozen to prevent hatching, and the nematode, Rhabditella leptura. This procedure has been adapted from Rodriguez, Wade and Wells ('62).

The small size and hard exoskeleton of this mite, which prevents penetration of fixatives, necessitated the development of a microdissection technique that would insure proper fixation of the excretory tubes and yet allow them to be removed intact. This enabled all areas of the tubes to be 
studied in a more precise manner. For this technique mites were immobilized in stendor dishes by carefully melting, with a hot needle, a small amount of paraffin around each leg. Mites appearing moribund were rejected. The remaining mites were then prechilled for about 30 minutes (Pease, '64) and flooded with fixative consisting of $2.5 \%$ glutaraldehyde in a $0.05 \mathrm{M}$ sodium cacodylate buffer ( $\mathrm{pH} 7.2$ ) containing 0.15 M sucrose. Using microscalpels made from razor blades and electrolytically sharpened tungsten wire probes (Brady, '65), the dorsal shield of each mite was removed and the internal organs exposed. After an initial half hour period of fixation, the excretory tubes were dissected out. They were immediately cut into several smaller pieces, and placed in fresh glutaraldehyde fixative for one to two hours. The tissue was then washed in the sodium cacodylate buffer containing $0.30 \mathrm{M}$ sucrose for four to eight hours and postfixed in $1 \%$ osmium tetroxide in veronal acetate buffer ( $\mathrm{pH} 7.2$ ) containing $0.30 \mathrm{M}$ sucrose. Following postfixation, the tissue was dehydrated in a graded series of ethyl alcohols. After three changes of propylene oxide, the tissue was infiltrated and embedded in Epon 812 according to the method of Luft ('61). All steps in this procedure prior to dehydration in absolute ethyl alcohol were carried out at a temperature of from $2^{\circ}$ to $6^{\circ} \mathrm{C}$.

Histochemical localization of acid phosphatase at the fine structural level was accomplished using a Gomori medium. The procedure of Miller and Palade ('64) was followed except that whole excretory tubes and not frozen tissue sections were used, and the incubation time in the Gomori medium was extended to 25 minutes. Controls were obtained by omitting the incubation medium.

Tissue blocks were sectioned using either a Reichert OmU2 or a MT-1 Sorvall "Porter-Blum" ultramicrotome. Both were equipped with diamond knives. Tissue sections mounted on 200 mesh copper grids were double stained in saturated uranyl acetate in $50 \%$ ethyl alcohol (10 minutes), and lead citrate ( 8 minutes) formulated according to Venable and Coggeshall ('65). Sections were examined with either a Sie- mens Elmiskop II at $50 \mathrm{kV}$, or a Siemens Elmiskop 1-A at $80 \mathrm{kV}$.

\section{RESULTS}

The paired excretory tubes of this mite are about $1.5 \mathrm{~mm}$ in length, and vary in width from 30 to $270 \mu$. These tubes extend from their junction with the rectal bulb to blind endings in the anterior of the body cavity (fig. 1). Here, they are attached to the body wall by a small filament of connective tissue. The epithelial cells of the excretory tubes protrude into the lumen. The excretory product, which is present in the lumen, is visible through the integument of the mite as a white granular substance. This is well illustrated by the photomicrographs of Rodriguez and Wade ('61) in which the excretory tubes, appearing as opaque structures, are incorrectly referred to as the gut.

A three dimensional reconstruction of a wedge-shaped section of an excretory tube cell is shown in figure 2 . A branching muscle system surrounds the cell. Each cell may be divided into three distinct morphological regions: a basal region bordering the hemocoel and possessing a highly infolded plasma membrane; next an intermediate region; and, bordering the lumen of the excretory tube, an apical region characterized by plate-like folds of the plasma membrane which we term microlamellae.

Fat body sheath and muscle system. The epithelial cells of the excretory tubes are surrounded by a muscle system and ensheathed by fat body. The fat body has a structure similar to that of the fat body of insects (Smith, '68). The ensheathment of the excretory tubes is only partial, leaving large areas of the tubes open to be bathed by the fluid in the body cavity (fig. 3). In cross sections of muscle fibers the sarcoplasmic reticulum and T-tube system are much reduced and often absent (figs. 4, 5). The ultrastructure of these muscle fibers resembles the insect visceral muscle fibers described by Smith, Gupta and Smith ('66). Separate circular or longitudinal fibers were not observed in the muscle system around the excretory tubes. Occasionally, both longitudinal and cross sectional profiles of fibrils within the same muscle fiber were found. This is suggestive of a branching type of visceral muscle system as in 
the Malpighian tubules of the honeybee (Morison, '27). The visceral muscle system of the excretory tubes is reconstructed in a diagrammatic fashion in figure 2 .

Excretory tube cells. The basal area of each epithelial cell rests on a basement membrane that is about $0.13 \mu$ thick (fig. 3 ). No connective tissue fibers could be demonstrated and it appears to be composed of an amorphous extracellular substance. This area of the cell is divided into many compartments by the infoldings of the plasma membrane (fig. 3). These occur at right angles to the basement membrane and extend about one third of the distance between the outer cell surface and the lumen of the excretory tube. Often, islets of cytoplasm are created by this compartmentalization (figs. 4,5). The infolded plasma membranes are separated by a distance of about $0.016 \mu$, except at the cell surface where the openings have a wider and more variable space. The basement membrane follows the contour of the cell surface but does not infold with the plasma membrane.

The most abundant organelles found in the cytoplasm are the mitochondria. They range over a wide variety of sizes and shapes. Often, mitochondria are closely associated with the compartments formed by the infolded plasma membrane (fig. 3). Two distinct morphological types of mitochondria were observed. The type most commonly encountered were normal in appearance, having a uniformly electron dense matrix and well developed cristae. Less commonly, mitochondria with an altered structure were observed. These were distributed throughout the length of the tubes. Within individual cells the altered mitocondria were found in the basal area (fig. 4), the intermediate area (fig. 5), and the apical area (figs. 6, 7). They were found in all areas of the cell where normal-appearing mitochondria are present. Myelinlike figures appear within the matrix of many of the altered mitochondria (figs. 4, $5,6,7)$. In the immediate vicinity of these figures, the matrix is electron lucent. In many of these altered mitochondria the cristae are poorly developed and often found only near the periphery of the matrix. Rarely mitochondria with a translucent matrix and somewhat poorly devel- oped cristae but without the myelin-like formations were encountered (fig. 5).

Because of the poor sampling powers of the techniques associated with electron microscopy, it was not possible to follow an individual mitochondrion throughout its structure. It is possible, therefore, that the mitochondria showing only an electron lucent matrix actually possess myelin-like figures. The altered mitochondria are somewhat larger than the surrounding mitochondria.

In the region of the cell between the basal area and the apical region which borders the lumen of the excretory tube, a large oval or spheroid nucleus is found (fig. 5). Other constituents of the cytoplasm commonly found in this region of the cell are vacuolar inclusions, lysosomes and Golgi bodies. The vacuolar inclusions are bounded by a single membrane (fig. 3 ). Although they are distributed throughout the cell, they are most commonly found in close association with the compartments of the basal area. The contents of the vacuolar inclusions appear to have been lost during preparation of the tissue. The lysosomes are also bounded by a single membrane (fig. 9). They most often appear in groups, commonly near the apical area of the cell. In tissue assayed for acid phosphatase, the reaction product appeared in the lysosomes as a dense precipitate which was most common along the limiting membrane (fig. 10). Controls failed to show the reaction product. Because of the difficulty of identifying lysosomes on the basis of their morphology alone, this enzyme is used as a marker. Electron dense bodies of varying sizes are found within the lysosomes. The Golgi bodies are not associated with the basal or apical region of the cell, but are found scattered throughout the area between the two regions (figs. 4, 5). Free ribosomes appear throughout the cytoplasm of the cell, and granular endoplasmic reticulum (fig. 5) which is often associated with mitochondria.

The apical region of the cell, next to the lumen of the excretory tube, has a border that consists of flat plate-like folds of the plasma membrane termed microlamellae (figs. 6, 7, 8, 9). Although transverse, longitudinal, and oblique sections through 
this area of the epithelial cells were studied, these folds never showed circular or elliptical profiles characteristic of the finger-like microvilli. The microlamellae vary in length from about $0.75 \mu$ to $1.50 \mu$. They have a width of about $0.056 \mu$. Some microlamellae appear to branch, but probably have a common origin on a raised area of tissue that is out of the plane of section. Curves are often found along the length of the longer microlamellae. The cytoplasm of the microlamellae does not contain any of the organelles that were described as being present in the rest of the cytoplasm. Between many of the microlamellae, small pits are present which appear to lead back some distance into the cytoplasm (figs. 6, 7). Rarely, microlamellae appear to loop back and join the cell proper (fig. 6).

Cell to cell junctional specialization between the epithelial cells of the excretory tube consist of a tight junction or zona occludens (fig. 4). These have a typical structure, with an obliterated intercellular space and a thickened inner leaflet of the plasma membrane. No other type of specialization at the site of cellular junction was observed.

Throughout the length of the excretory tubes, no major ultrastructural differences were observed. Minor differences do occur, especially where a local accumulation of the excretory product results in a distension of the adjacent cells. In these areas, the infoldings of the plasma membranes in the basal region of the cell and the development of the lamellar border of the apical region of the cell is not as extensive. Although these distended areas are found all along the excretory tubes, they are most common in the region just prior to the junction of the tube with the rectal bulb.

Lumen of the excretory tubes. The lumen of the excretory tubes contains abundant bodies of round, spherical, or rectangular shapes (figs. 11, 12). Filamentous strands were sometimes observed in the lumen, and these were associated with both the microlamellae and the bodies found in the lumen (fig. 11). Often these bodies failed to infiltrate properly with the plastic embedding media (fig. 12). In the light microscope, they appear as highly refractive particles. They make up the white granular excretory product the lumen of the excretory tubes.

\section{DISCUSSION}

The ultrastructure of the Malpighian tubules of insects have been the subject of a number of investigations (refs. in Smith, '68). The excretory organs of different crustaceans have also received attention from electron microscopists (Beams, Tahmisian and Devine, '55; Anderson and Beams, '56; Schmidt-Nielsen, Gertz and Davis, '68). Other arthropod groups have not been as extensively investigated, and to our knowledge, no ultrastructural study of the excretory organs of mites has been reported.

Studies to date have shown that arthropod excretory organs have in common cells possessing a basal region with an infolded plasma membrane, a cytoplasm containing large numbers of well developed mitochondria, and an apical region having a series of complex folds. This general description also applies to the cells of the excretory tubes of $M$. muscaedomesticae.

More specifically, the epithelium of the Malpighian tubules of insects have been found to be of two types. It may be similar, with only minor differences throughout its length, as in this mite, or it may be differentiated into morphological regions. The simple type of epithelium is best seen in the grasshoppers Melanoplus differentialis differentialis (Beams, Tahmisan and Devine, '55), and Dissoteira carolina (Tsubo and Brandt, '62). The more complex type having distinct regions is found in the leafhopper Macrosteles fascifrons (Smith and Littau, '60), the immatures of the olive fruit fly Dacus oleae (Mazzi and Baccetti, '63), and the reduviid bug Rhodnius prolixus (Wigglesworth and Salpeter, '62). In Macrosteles, three types of cells were found in four regions of the tubules, while in Dacus, four distinct regions were found in the anterior pair of tubules, but only two distinct regions in the posterior pair of tubules. In Rhodnius, the upper segment of the Malpighian tubules has a striated border with closely packed elements, and an apical region in which mitochondria are much more abundant than in the rest of the cell. The lower segment of the tubules has a brush border composed of elements 
that are more variable in structure and more widely spaced. Mitochondria in this area are more commonly associated with the basal area of the cell. It is suggested by these authors that the distribution of mitochondria reflects the difference in the direction of active transport between cells in the two regions.

In the Malpighian tubules of several insects, mitochondria with altered structures have been reported. Dense homogenous bodies were observed in Macrosteles fascifrons (Smith and Littau, '60). It was suggested that they represent degenerating mitochondria. Wessing ('62) has described the process of mitochondrial degeneration in the cells of Malpighian tubules of larval, pupal and adult Drosophila melanogaster. This process was divided into a number of stages, one of which was marked by the appearance of lamellar whorls within the mitochondria. These lamellae ultimately become dissolved, and often a mitochondrion with a nearly homogenous content resulted. This complex process was most common in the developing stages of the vinegar gnat. Wessing states that these stages have an increased metabolism. Other investigations on insects that have altered mitochondria in their Malpighian tubules are discussed below in connection with the formation of the excretory granules.

Intramitochondrial bodies of several different types have been reported in a number of kinds of cells from a variety of animals other than insects. Wessing ('62) gives a number of references and more recently Suzuki and Mostofi ('67) have classified these inclusions with respect to their structure and localization within the mitochondria.

Myelin-like figures within mitochondria have been reported by a number of workers. The results of their studies have been discussed by Beux, Hetenyi and Phillips ('69), who also studied intramitochondrial myelin-like formations in the liver cells of rats under a variety of experimental conditions. While noting that these formations have been produced under a variety of experimental conditions and are considered by some workers to indicate mitochondrial regeneration or biogenesis (Beck and Grennawalt, '68; Pannese, '66), Beux et al. believe that myelin-like figures occur normally but are enhanced by such different stimuli as fasting, glucose infusion and insulin administration.

It is believed that the altered mitochondria found in the excretory tubes of $M$. muscaedomesticae represent part of a normal process of mitochondrial degeneration. That this process was observed at all is probably due to the large number of mitochondria present. It is possible that these altered mitochondria are merely artifacts introduced by the techniques necessary to prepare the tissue for study in the electron microscope. Because of the normal appearance of the cytoplasm surrounding the altered mitochondria, it is difficult to account for them as such. In addition, altered mitochondria were not observed in the cells of other organ systems of this mite. The static nature of electron microscopy makes analysis of dynamic processes difficult. However, in this study, micrographs show that altered mitochondria exhibit varying amounts of myelin-like figures. This suggests that there are intermediate forms of the altered mitochondria and that the change is a progressive one.

One of the most unusual morphological features of the excretory tubes of this mite is the lamellar border of the apical area of the cell which is made up of flat platelike microlamellae. A lamellar border, as opposed to a striated or brush border, has been described in the apical area of cells from several organ systems of insects. Smith and Littau ('60) found this type of border in two of the four regions of the Malpighian tubules and throughout the hindgut of Macrosteles fascifrons. In the Malpighian tubules, this type of border was found in flask-like depressions of the apical surface of the cells. In the hindgut, the lamellar border was arranged almost at a right angle to the long axis of the lumen. Mitochondria are found within the individual leaflets of the border in the hindgut but are absent from those of the Malpighian tubules.

A lamellar border is also found in the apical area of lipophilic cells in the midgut of Australian sheep blowfly larvae, Lucilia cuprina (Waterhouse and Wright, '60). This border most closely resembles that of the excretory tubes of this mite. The cyto- 
plasm of both borders does not contain any cellular organelles. Most conspicuous is the absence of mitochondria, a common component of the cytoplasm of the microvillae of the Malpighian tubules of insects and, as noted above, the lamellar border of the hindgut of Macrosteles fascifrons. Curves are present along the length of the microlamellae in the blowfly larvae, and are found in the longer microlamellae in $M$. muscaedomesticae. The curves are much more common and more pronounced in the blowfly larvae. Neither border has any pinocytotic vesicles as are found in the microvillae of the grasshopper Dissosteira carolina (Tsubo and Brandt, '62). It is believed that these vesicles are involved in the movement of large molecules across the cell.

The intracellular formation of the excretory granules that are ultimately deposited in the lumen has been described in at least two insects. Berkaloff ('58; '59a,b; '60) found that the intracellular formation of globule pigments in the tubules of Gryllus domesticus results from changes in the mitochondria. In the lumen, these pigments appear as concentric laminated structures. Wigglesworth and Salpeter ('62) suggest that the mineralized granules found in the lumen of the tubules of Rhodnius prolixus are the results of the breakdown of mitochondria.

It was not possible to correlate any structure or process of the cells of the excretory tubes of this mite with the formation of the granules observed in the lumen. It is most likely that in this mite the nitrogenous

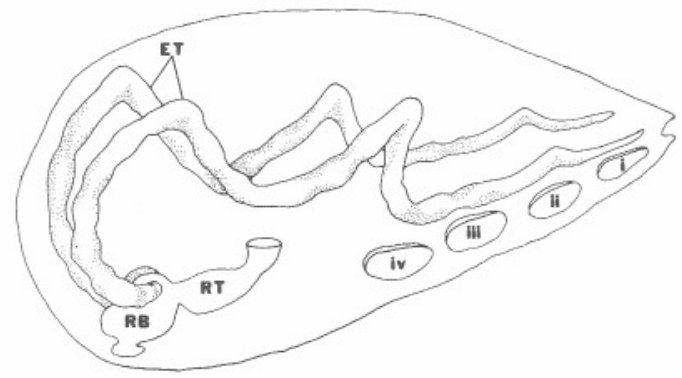

Fig. 1 Diagramatic representation of the excretory tubes (ET). Numbered circles indicate the position of the four pairs of legs. Only the rectal tube (RT) and rectal bulb (RB) of the digestive system are shown. wastes pass through the cytoplasm of the cells of the excretory tubes in a soluble form which is changed into the insoluble granules in the lumen.

\section{ACKNOWLEDGMENTS}

This research was supported in part by U. S. Public Health Service Research grant EC-246 from The Environmental Control Administration, training grant ES00069 from the National Institute of Environmental Health Sciences and by the Office of Naval Research Department of the Navy. This is paper 3278 of the Journal Series of the North Carolina State University Agricultural Experiment Station.

\section{LITERATURE CITED}

Anderson, E., and H. W. Beams 1956 Light and electron microscope studies on the cells of the labyrinth in the "green gland" of Cambarus sp. Proc. Iowa Acad. Sci., 63: 681-685.

Baker, E. W., and G. W. Wharton 1952 An Introduction to Acarology. The Macmillian Co., New York.

Beams, H. W., T. N. Tahmisian and R. L. Devine 1955 Electron microscope studies on the cells of the Malpighian tubules of the grasshopper (Orthoptera, Acrididae). J. Biophys. Biochem. Cytol., 1: 197-202.

Beck, D. P., and J. W. Greenawalt 1968 Factors affecting the formation of membranous structures in the cytoplasm and mitochondria of Neurospora crassa. J. Cell Biol., 39: 11a.

Berkaloff, A. 1958 Les grains de secretion des tubes de Gryllus domesticus (Orthopere, Gryllidae). C. R. Acad. Sci., Paris, 246: 2807-2809.

1959a Transformations mitochondriales et formation de pigment dans les tubes de Malpighi de Gryllus domesticus (Orthoptere, Gryllidae). C. R. Acad. Sci., Paris, 249: 1934-1936. 1959b Repartition de la phosphatase alcaline et des grains de secretion dans les tubes de Malpighi de Gryllus domesticus (Orthoptere, Gryllidae). C. R. Acad. Sci., Paris, 249: 2120-2121.

1960 Contribution a l'excrétion chez les insects. Annis. Sci. Nat., 12: 869-942.

Beux, Yvi Le, G. Hetenyi, Jr. and M. J. Phillips 1969 Mitochondrial myelin-like figures: a nonspecific reactive process of mitochondrial phospholipid membranes to several stimuli. Z. Zellforsch., 99: 491-506.

Brady, J. 1965 A simple technique for making very fine durable dissecting needles by sharpening tungsten wire electrolytically. Bull. Wld. Health Or., 32: 143-144.

Luft, J. H. 1961 Improvements in epoxy resin embedding methods. J. Biophys. Biochem., Crytol., 9: 409-414.

Mazzi, V., and B. Baccetti 1963 Ricerche istochimiche e al microscopio elettronico sui tubi Malpighiani di Dacus oleae Gmel. I. La larva. Z. Zellforsch., 59: 47-70. 
Miller, F., and G. E. Palade 1964 Lytic activities in renal protein adsorption droplets. An electron microscopical cytochemical study. J. Cell Biol., 23: 519-552.

Morison, G. C. 1927 The muscles of the adult honey-bee. Part II. The healthy muscles of the adult honey-bee. Muscles of the alimentary canal, heart, diaphragms, and the reproductive organs, and the indirect muscles of the wings. Q. J. Microsc. Sci., 71: 563-651.

Pannese, E. 1966 Structures possibly related to the formation of new mitochondria in spinal ganglion neuroblasts. J. Ultrastr. Res., 15: 5765.

Pease, D. C. 1964 Histological Techniques for Electron Microscopy. Academic Press, New York.

Rodriguez, J. G., and C. F. Wade 1961 The nutrition of Macrocheles muscaedomesticae (Acarina: Macrochelidae) in relation to its predatory action on the house fly egg. Ann. Entomol. Soc. Am., 54: 782-788.

Rodriguez, J. G., C. F. Wade and C. N. Wells 1962 Nematodes as a natural food for Macrocheles muscaedomesticae (Acarina: Macrochelidae), a predator of the house fly egg. Ann. Entomol. Soc. Amer., 55: 507-511.

Schmidt-Nielsen, B., K. H. Gertz and L. E. Davis 1968 Excretion and ultrastructure of the an. tennal gland of the fiddler crab Uca mordax. J. Morph., 125: 473-495.
Smith, D. S. 1968 Insect Cells, Their Structure and Function. Oliver and Boyd, London.

Smith, D. S., B. L. Gupta and U. Smith 1966 The organization and myofilament array of insect visceral muscles. J. Cell Sci., 1: 49-57.

Smith, D. S., and V. C. Littau 1960 Cellular specialization in the excretory epithelia of an insect, Macrosteles fascifrons Stal (Homoptera). J. Biophys. Biochem. Cyłol., 8: 103-133.

Susuki, T., and F. K. Mostofi 1967 Intramitochondrial filamentous bodies in the thick limb of Henle of the rat kidney. J. Cell Biol., 33: $605-623$.

Tsubo, I., and P. W. Brandt 1962 An electron microscopic study of the Malpighian tubules of the grasshopper Dissosteira carolina. J. Ultrastr. Res., 6: 28-35.

Venable, J. H., and R. Coggeshall 1965 A simplified lead citrate stain for use in electron microscopy. J. Cell Biol., 25: 407-408.

Waterhouse, D. F., and M. Wright 1960 The fine structure of the mosaic midgut epithelium of blowfly larvae. J. Insect Physiol., 5: 230-239.

Wessing, A. 1962 Die Transformation der Mitochondrien in den Malpighischen GefaBen von Drosophila melanogaster. Protoplasma, 55: 294304.

Wigglesworth, V. B., and M. M. Salpeter 1962 Histology of the Malpighian tubules in Rhodnius prolixus Stal (Hemiptera). J. Insect. Physiol., 8: 299-307. 
PLATE 1

OF MITE EXCRETORY TUBES

ULThAsInUCrune Richard C. Axtel

Lewis

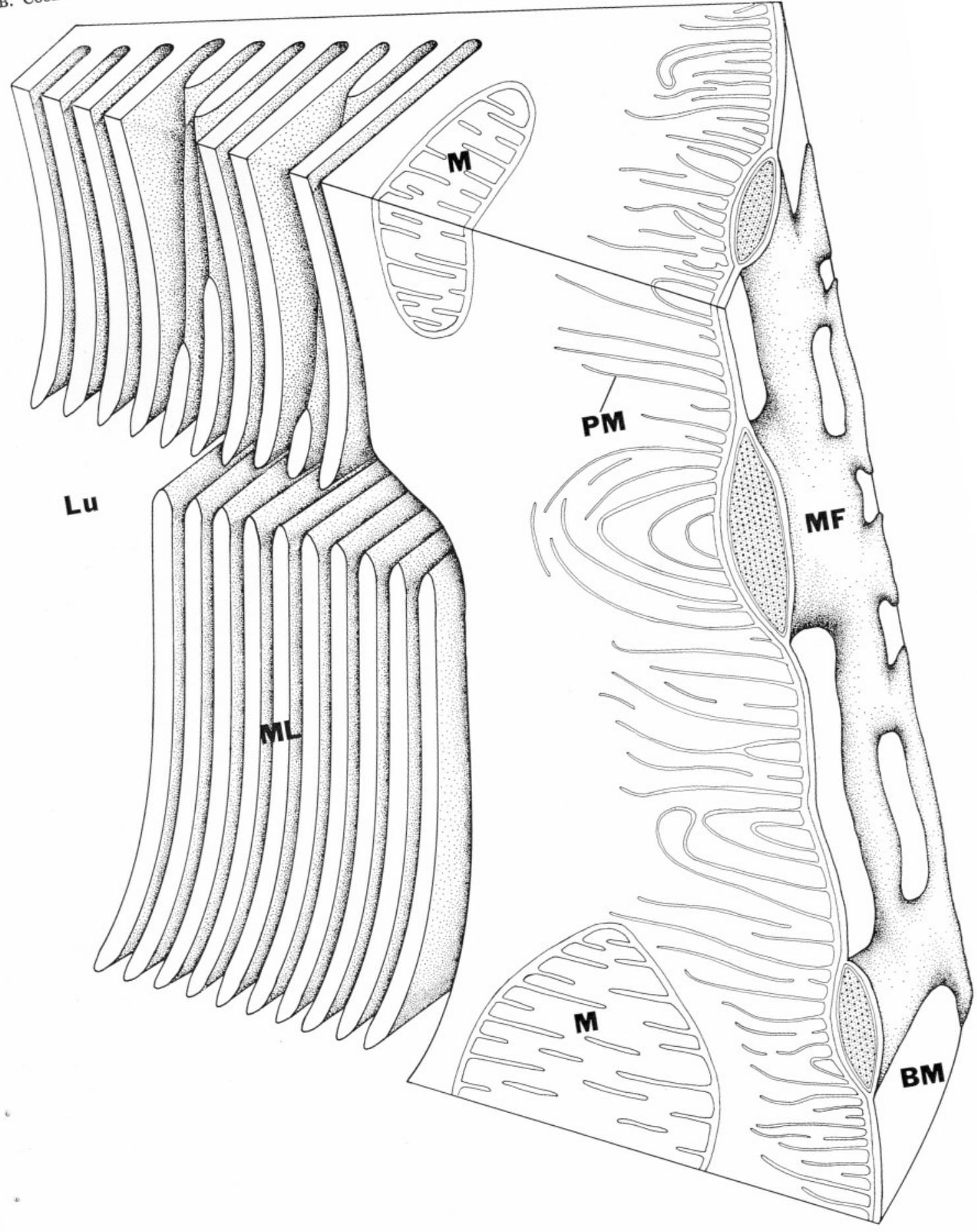


PLATE 2

EXPLANATION OF FIGURE

3 The basal area of an excretory tube cell which is partially ensheathed with fat body (FB). The cell rests on an amorphous basement membrane (BM). The plasma membrane (PM) of the excretory cell infolds at right angles to the basement membrane dividing this area of the cell into many compartments. Mitochondria (M) with well developed cristae, and vacuolar inclusions (VI), are closely associated with the infolded plasma membrane. $\times 24,000$. 


\section{Abbreviations}

BM, basement membrane

$\mathrm{EP}$, excretory product

MF, visceral muscle fibers

ER, rough endoplasmic

ML, microlamellae reticulum

ET, excretory tubes

FB, fat body

G, Golgi bodies

$\mathrm{Lu}$, lumen

$\mathrm{N}$, nucleus

PM, plasma membrane

$\mathrm{RB}$, rectal bulb

RT, rectal tube

TJ, tight junction

M, mitochondria

VI, vacuolar inclusions

PLATE 1

EXPLANATION OF FIGURE

2 Diagramatic three dimensional representation of a wedge-shaped section from an excretory tube cell. Visceral muscle fibers (MF), in the form of a branching synctium, invest the cell. A basement membrane (BM) surrounds the muscle system and the basal region of the cell. The plasma membrane (PM) in this region infolds and often this creates islets of cytoplasm. Mitochondria (M) are common throughout the cell. The apical area of the cell is thrown into a series of platelike folds or microlamellae (ML) that project into the lumen ( $\mathrm{Lu}$ ) of the tube. 


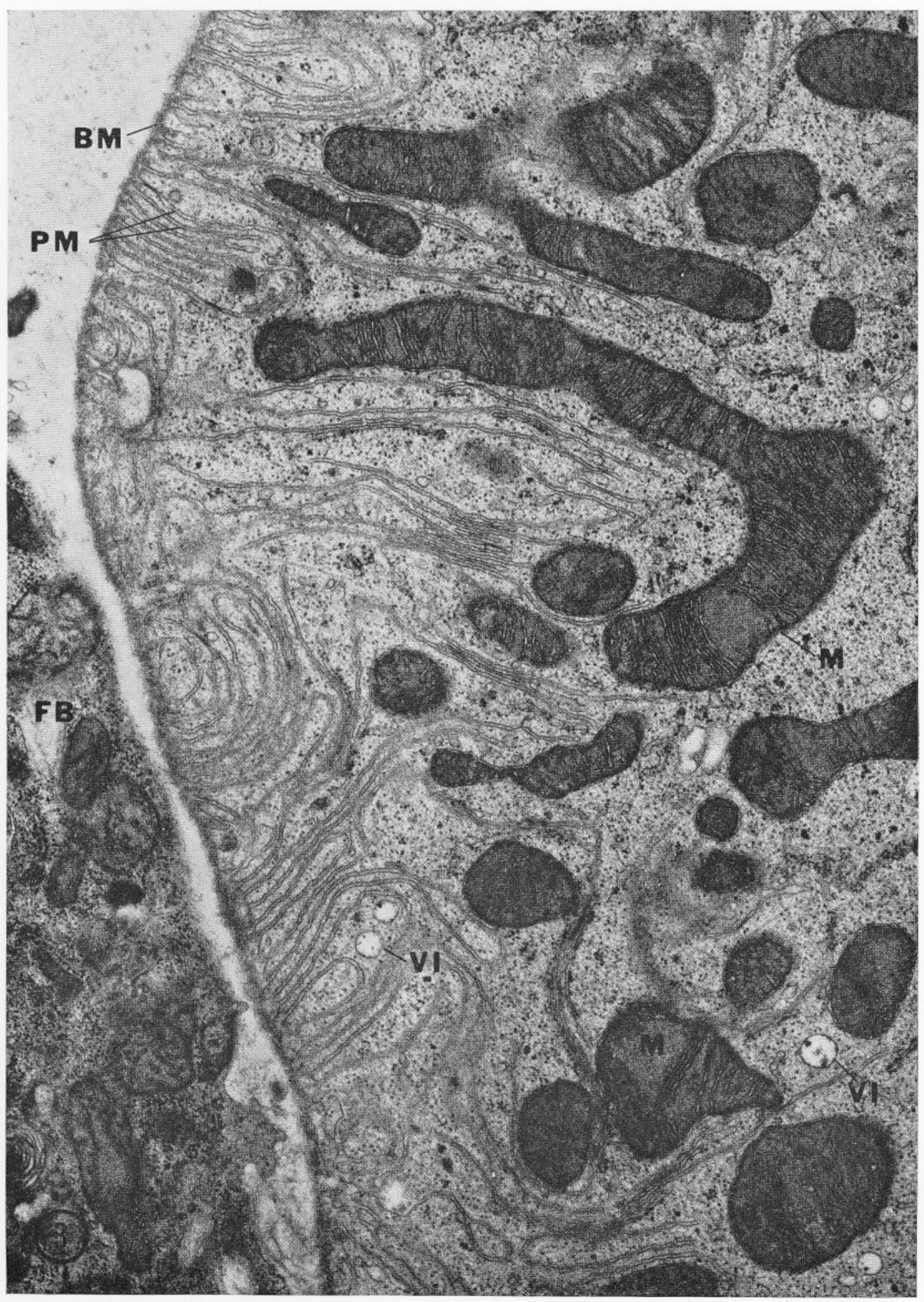


4-5 A region showing the basal and intermediate areas of two different cells of the excretory tube. Large mitochondria $\left(\mathrm{M}^{\prime}\right)$ are shown which have electron lucent matrices and few cristae that are generally restricted to the periphery. Myelin-like inclusions are found in two of the large mitochondria. Other structures identified in the micrographs are infolding of the plasma membrane (PM), Golgi bodies (G), and muscle fibers (MF). In figure 4, a tight junction (TJ), and in figure 5, rough endoplasmic reticulum (ER), and part of a nucleus (N) are shown. $\times 16,000$. 
6-7 A region showing the apical area of two different cells of the excretory tube. Large mitochondria $\left(\mathrm{M}^{\prime}\right)$ with electron lucent matrices and myelin inclusions are present. A mitochondrion (M) with a typical structure is shown in figure 6. The mitochondrion in figure 7 with the large myelin-like inclusion has few cristae that are generally restricted to the periphery. Microlamellae (ML) are shown projecting into the lumen ( $\mathrm{Lu}$ ) of the excretory tube. Small pits (arrows) are present between the microlamellae and appear to lead some distance back into the cytoplasm. In figure 6, one microlamella (double arrow) appears to loop back and join the cell proper. $\times 20,000$. 

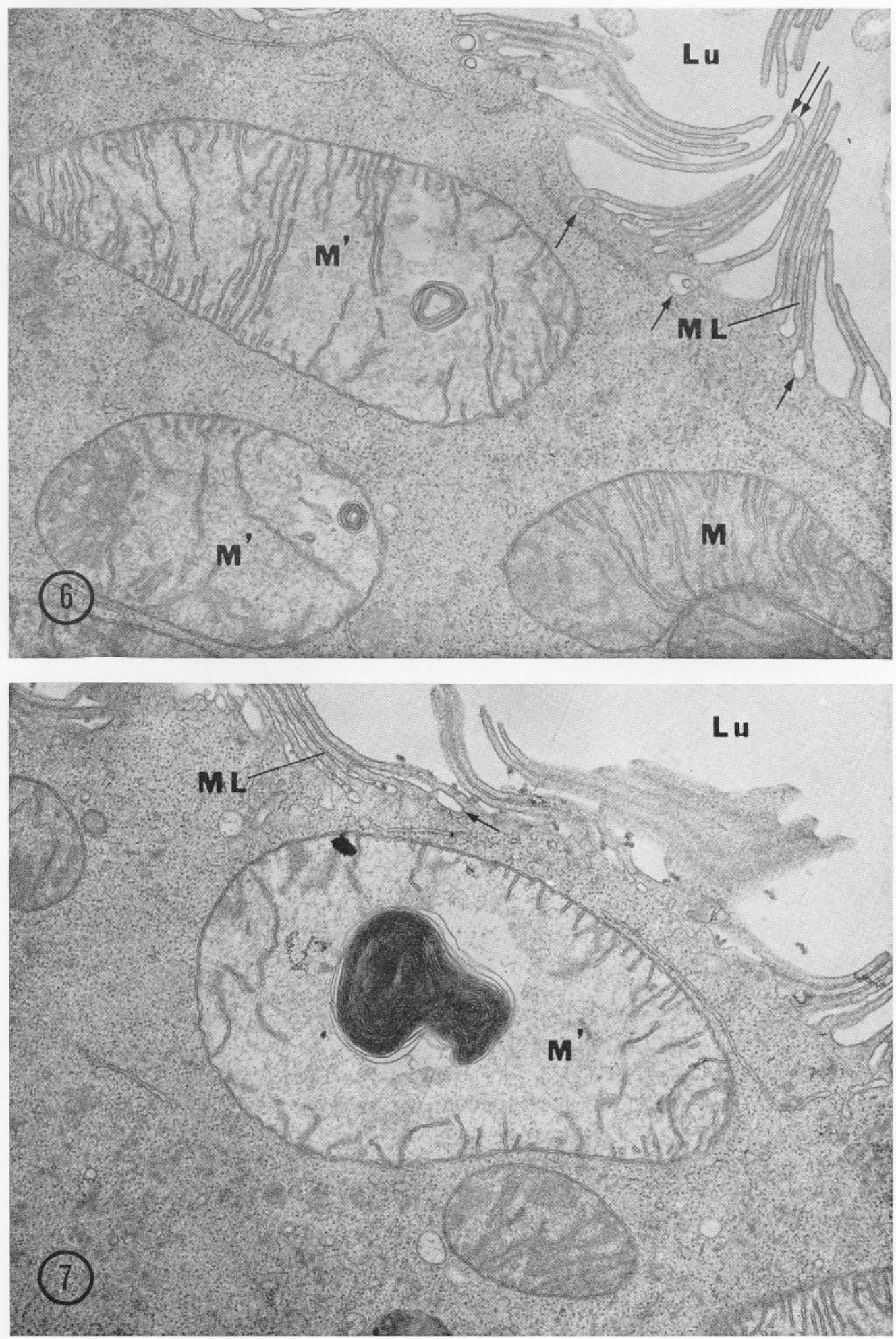


\section{PLATE 5 \\ EXPLANATION OF FIGURE}

8 High magnification electron micrograph of a group of microlamellae (ML) which project into the lumen ( $\mathrm{Lu})$. This micrograph illustrates the uniformity of the cytoplasm and the paucity of cellular organelles within the microlamellae. A mitochondrion (M) is also identified. $\times 150,000$. 


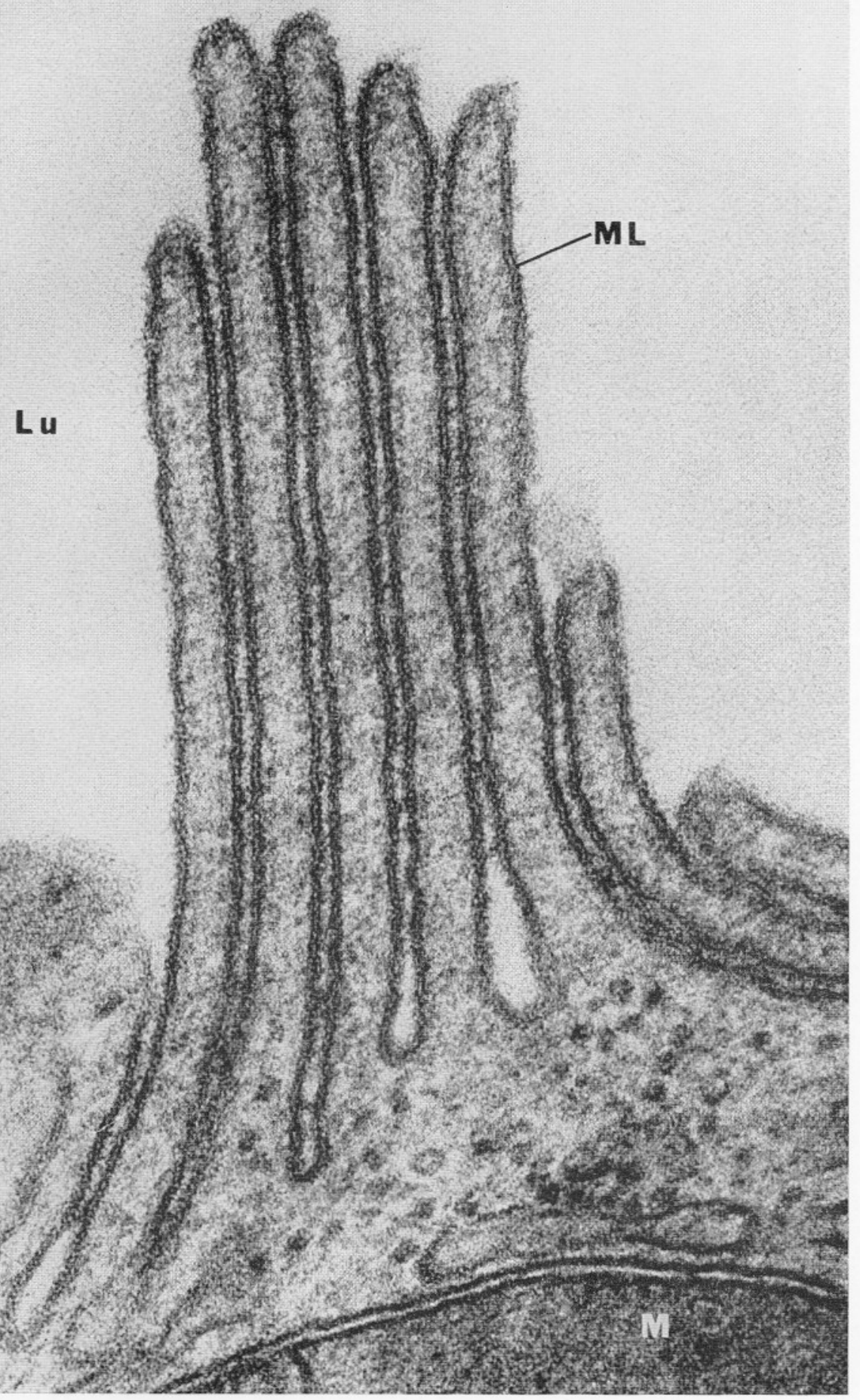


9 Cross-section of an excretory tube cell showing a group of lysosomes (arrows). Each is bounded by a single membrane and contains many round bodies of varying degrees of size and electron density. Microlamellae (ML) which make up the border of the apical region of the cell and project into the lumen of the excretory tube are also identified. $\times 20,000$.

10 Electron micrograph showing lysosomes that have a dense precipitate of acid phosphatase reaction product. This deposit is most common along the limiting membrane. $\times 30,000$.

11-12 Electron micrographs of the lumen of the excretory tube showing the excretory product (EP). In figure 11, filamentous strands (arrows) are associated with both the microlamellae (ML) and the excretory products. Often, as shown in figure 12 (asterisk), the excretory product fails to infiltrate properly. Figure $11 \times 40,000$; figure $12 \times 20,000$. 

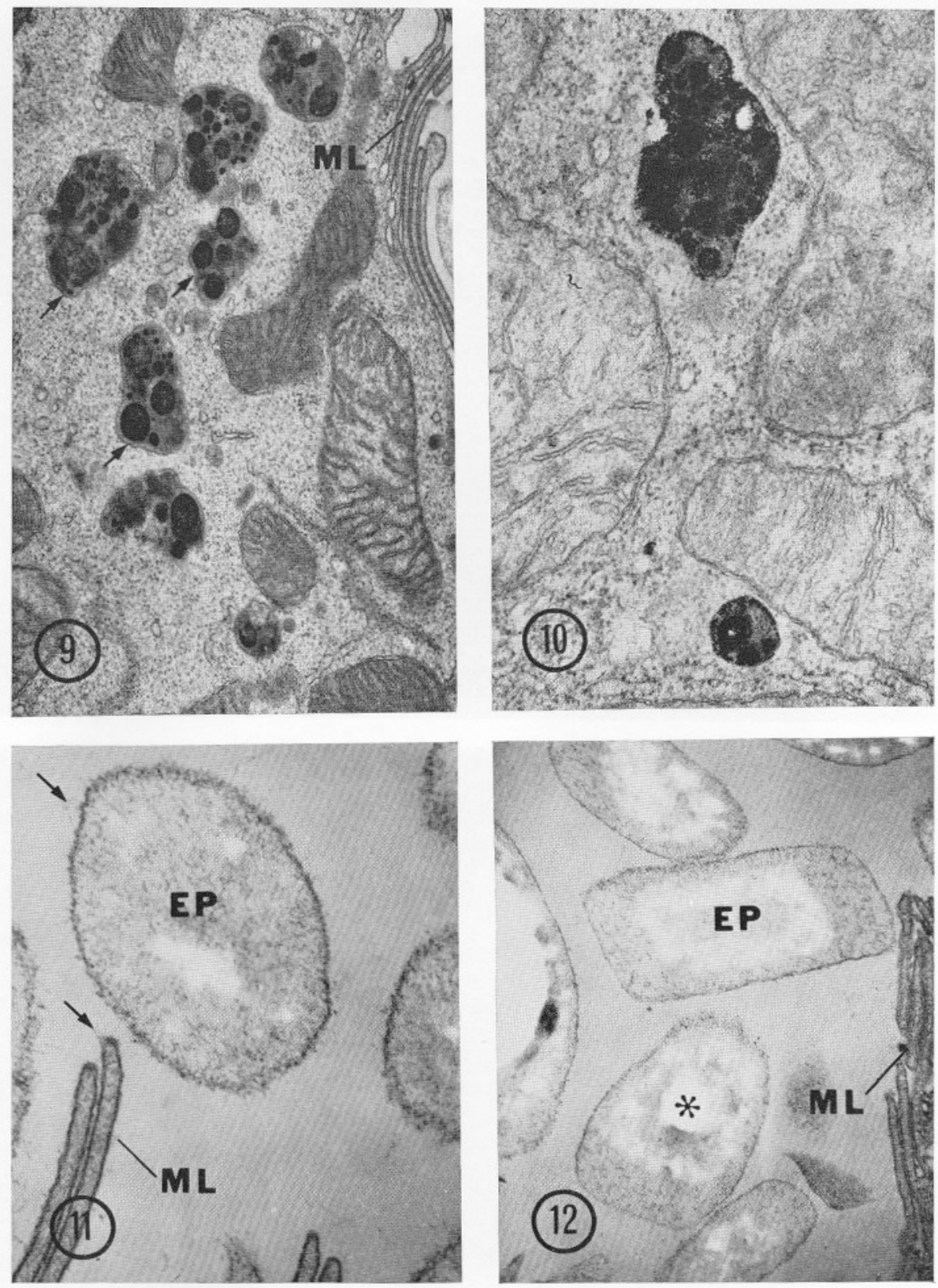
